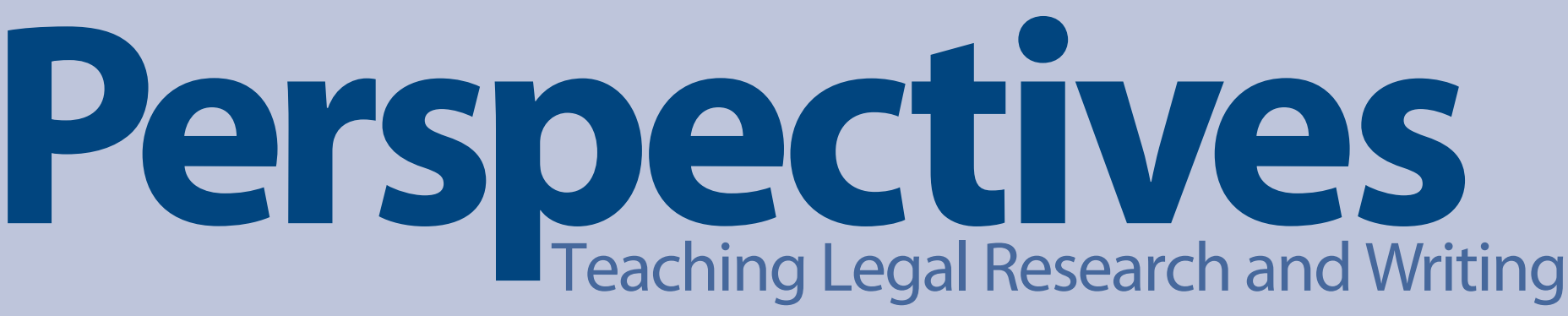

Vol. 22 | No. 2 | Spring 2014

Cite as: Ellie Margolis and Kristen Murray, Teaching Research Using an Information Literacy Paradigm, 22 Perspectives: Teaching Legal Res. \& Writing 101 (2014).

\title{
Teaching Research Using an Information Literacy Paradigm
}

By Ellie Margolis and Kristen Murray

Ellie Margolis is Professor of Law and Kristen Murray is Associate Professor of Law at Temple University, Beasley School of Law in Philadelphia, Pa.

\section{Introduction}

Should you still teach research in books? When do you introduce free online research tools? How do you cover all of the different research methods? These are the questions legal research professors have asked increasingly in the past few years. The explosion in the number of legal research tools available has changed the nature of legal research and at the same time students are entering school as digital natives, conversant in online research technologies. We began to feel that traditional legal research pedagogy was no longer the most effective way to teach today's law students. In particular, it started to seem antiquated-quaint, even-to begin teaching legal research by using books.

It was time to think about a whole new approach to teaching research methods to these students in this new environment. Ultimately, we concluded that information literacy provides the ideal framework for a new paradigm for legal research pedagogy, to ensure that we continue to provide effective legal research instruction in an increasingly electronic research world. ${ }^{1}$

Information literacy is the "ability to identify what information is needed, understand how the information is organized, identify the best sources of information for a given need, locate those sources, evaluate the sources critically,

1 Thomas Keefe, Teaching Legal Research from the Inside Out, 97 Law Libr. J. 117, 121-122(2005). and share that information." By focusing on information literacy, rather than specific research techniques or finding tools, we can give our students the skills they will need to cope with the ever-changing research environment.

\section{Information Literacy: Background}

Legal research has been taught the same way for many years: students are taught a multistep, linear research process that usually begins with secondary sources and ends with updating the primary authorities the researcher has found. Even as more information became available

2 What is Information Literacy?, University of Idaho: Information Literacy Portal, http://www.webs.uidaho.edu/info_ literacy/ (last visited June 17, 2013). 
101 Teaching Research Using an Information Literacy Paradigm

Ellie Margolis and Kristen Murray

107 The Missing Piece: Teaching Cost Recovery as Part of Cost-Effective Research Kathleen Darvil \& Sara Gras

112 Diversifying the First-Year Skills Coverage by Creating Three Separate Tracks for $1 \mathrm{Ls}$ Tracy L. Turner

\section{Oral Advocacy in 90 Seconds: Turning}

\section{Fear into Fun}

Jill Barton

118 Incorporating Ethics into the Research Curriculum

Rima Sirota

\section{Timing is Everything: Teaching Essential} Time Management Skills for "Real-World” Legal

Writing

Camille Lamar Campbell

131 Teaching Active Listening: Flipping Roles in Client Interviewing Exercises

Tenielle Fordyce-Ruff

134 Doing Like the Locals Do: Using the Legal Writing Classroom to Teach Local-Rule Practice Cheryl S. Bratt

138 Using Federal Agency Advisory Letters As "Real-World" Writing Samples (and to Validate the Fundamental Legal Writing Principles We Teach) Tina Boudreaux

\section{Capitol Drafting: Legislative Drafting} Manuals in the Law School Classroom Amy Langenfeld

\section{Everything I Learned About Teaching} Legal Writing I Learned From Being a Parent Heather Baxter

\section{Working on Our Night Moves: Strategies} to Engage Evening Students

Rosario Lozada Schrier
Perspectives: Teaching Legal Research and Writing is published in the fall and spring of each year by West.

\section{Editor}

Elizabeth Edinger

Catholic University of America

Law Library

Washington, D.C.

\section{Editorial Board}

Kathryn S. Mercer

Case Western Reserve

University School of Law

Cleveland, Ohio

Suzanne Rowe

University of Oregon

Eugene, Oregon

Helene S. Shapo

Northwestern University

School of Law

Chicago, Illinois
Craig T. Smith

UNC School of Law

Helen M. Walker

Burr \& Forman LLP

Birmingham, AL

Jackie Woodside UC Irvine School of Law Irvine, California
Chapel Hill, North Carolina

Opinions expressed in this publication are those of the authors and should not be attributed to the Editor, the Editorial Board, or West.

Authors are encouraged to submit brief articles on subjects relevant to the teaching of legal research and writing. The Perspectives Author's Guide and Style Sheet are posted at http://info.legalsolutions. thomsonreuters.com/signup/newsletters/perspectives/ perstyle.aspx. Manuscripts, comments, and correspondence should be sent to:

Elizabeth Edinger, Associate Director, Catholic University of America Law Library, 3600 John McCormack Rd., N.E., Washington, DC 20064. Email: edinger@law.edu

http://info.legalsolutions.thomsonreuters.com/ signup/newsletters/9.aspx

Published by Thomson Reuters as a service to the Legal Community. 
online, the teaching of legal research almost always started with print-based sources, with some schools restricting online access until later in (or even after) the first semester. ${ }^{3}$ In the early days of digitization, the online databases replicated the organization of the print world, and legal research professors felt it was important to understand print sources in order to conduct effective online research.

Now, however, the organization of digital information no longer follows the organizational model found in the print world, and no longer do legal researchers need to replicate the printbased methods of accessing information online. Instead of selecting databases and using subject indexes to find legal information, the point of entry in electronic research is the search engine.

Thus, legal research has become at once easier and more challenging than it ever was in the past. At the same time that the print system has lost its hold on the organization of legal material, legal researchers are increasingly going directly to the Internet to conduct their research. ${ }^{4}$ While print materials have not been abandoned altogether, it is clear that they are used rarely. It is possible, and common, for legal research to be conducted entirely online. Most legal research courses have not yet caught up to this reality, however, and devote substantial time to teaching legal research in print. ${ }^{5}$

\footnotetext{
3 ALWD 2012 survey question 19, http://www.alwd.org/ wp-content/uploads/2013/02/2012-survey-results.pdf. Of the reporting schools, seventy offer limited Westlaw/Lexis training in the first semester.

4 Legal Tech. Res. Ctr., Am. Bar Ass'n, 2011 Legal Technology Survey Report: Online Research at V-x (2011) (Question 17) (showing that of those surveyed, only 13 percent begin their research in print sources) and V-xiv, V-38 (Question 20) (showing that 98 percent of respondents conduct legal research online).
}

5 Popular legal research texts continue to devote significant space to teaching print sources such as indexes, digests, legal encyclopedias, treatises, and annotated codes. See generally Nancy P. Johnson, Should You Use A Textbook To Teach Legal Research?, 103 Law Libr. J. 428435 (2011) (providing reviews of popular legal research texts); see also Steven M. Barkan et al., Fundamentals Of Legal Research, 78-80, 82-83, 232-33 (9th Ed. 2009); Laurel Currie Oates et al., Just Research, 46-48, 156-57, (2d Ed. 2009); Amy E. Sloan, Basic Legal Research: Tools And Strategies, 51, 74-76, 206-09 (5th Ed. 2012).
As these changes have developed, information literacy has emerged as a new way of thinking about research. The Association of College and Research Libraries (ACRL) defines information literacy as "the set of skills needed to find, retrieve, analyze, and use information.” An individual who is information literate has the skills to adapt to changes in the research environment and retain the ability of lifelong learning.

The ACRL standards identify five basic principles that transfer easily to the law school context. They are 1) possess fundamental research skills, 2) implement effective, efficient research strategies, 3) critically evaluate legal and nonlegal information, 4) apply information effectively to resolve a specific issue or need, and 5) distinguish between ethical and unethical uses of information and understand the legal issues arising from discovery and use of information. The first three of the principles are most closely related to the material generally covered in legal research courses. The final two, which involve the application of information and its ethical and legal uses, are more typically covered in instruction related to the writing, rather than research, process.

\section{Teaching Using an Information Literacy Paradigm}

As we began to consider the role information literacy should play in legal research instruction, we conducted a survey of incoming law students from twelve different law schools across the country in the fall of 2011. The goal of the survey was

6 Introduction to Information Literacy, Am. Library Ass'n, http:// www.ala.org/acrl/issues/infolit/overview/intro (last visited June 17, 2013).

$$
7 \text { Id. }
$$

8 Id.

9 The participating schools were: Drake University Law School; Elon University School of Law; George Washington University Law School; The John Marshall Law School; Northwestern University Law School; Shepard Broad Law Center, Nova Southeastern University; University of Pennsylvania Law School; University of South Carolina School of Law; Stetson University College of Law; Temple University, Beasley School of Law; University of Nevada-Las Vegas, William S. Boyd School of Law; and Wake Forest University School of Law.
${ }^{6}$... the

organization

of digital

information no

longer follows the

organizational

model found

in the print

world, ..." 
${ }^{66}$... incoming

law students are

ready to move

past traditional

research

instruction." to evaluate the incoming students' information

literacy and research practices and skills. ${ }^{10}$

Based on the survey results, we came to two major conclusions. First, these researchers might be more competent than conventional wisdom would have us think. Although many students lacked formal research training ${ }^{11}$ and made some choices based on convenience, ${ }^{12}$ they also claimed to have experience, proficiency, and high comfort levels with a wide variety of types of sources. ${ }^{13}$ Second, the baseline information contained in the survey also shows that incoming law students are ready to move past traditional research instruction. Generally speaking, the respondents expressed a definite preference and privileging of online sources, ${ }^{14}$ seemed less familiar and/or comfortable with a process-based research approach, and tended to eschew the idea of using a research plan or journal. ${ }^{15}$

Taken together, these results indicate that today's researchers have a firm foundation for learning through an information literacy paradigm. The survey results revealed that our students are competent and ready to begin using online research techniques when they arrive in law school; they arrive with some amount of information literacy, which we need to both increase and refine, so that they become literate with legal information. Given that the digital research world is ever-changing, we also need to equip our students with the skills they need to conduct research well beyond the confines of the first-year course. The technology our students encounter as first-years may look very different by the time they graduate and

10 The full survey results are available in Ellie Margolis and Kristen Murray, Say Goodbye to the Books: Information Literacy as the New Legal Research Paradigm, forthcoming, 38 U. Dayton L. Rev. (2013)

11 Ellie Margolis \& Kristen Murray, Information Literacy-The Next Wave of Legal Research Instruction (2011) [hereinafter "Survey Results"] (on file with author) (Question 9).

12 See, e.g., Survey Results, Question 28.

13 For example, the responses to Question 28 show highly literate answers regarding credibility and reliability of various sources.

14 See, e.g., Survey Results, Questions 13, 14, and 15.

15 See, e.g., Survey Results, Questions 17 and 29 move into practice. Information literacy provides a transferable framework so that basic competency levels are not source- or research method-specific.

With this in mind, we have developed five principles that will allow us to begin teaching using an information literacy paradigm. They are: (1) reframe the goal of teaching legal research; (2) focus on evaluating, not finding; (3) move away from linear research plans; (4) reframe what it means to learn by doing; and (5) rethink traditional approaches to the first-year course.

Principle No.1: Reframe the goal of teaching legal research.

In order to transition to an information literacy environment, it is first necessary for us to rethink the goal of teaching legal research. Previously, we assumed our students were blank slates, ready to be taught about legal sources using a linear, bibliographic method to learn the different types of sources and how to use them. Now, legal research professors should start to think of the goal of legal research instruction as, simply, to increase the level of information literacy in our students in the context of law; stated differently, we want them to develop high levels of legal information literacy.

Practically, this means we must let go of our own resistance to abandoning traditional research instruction for fear that the quality of research will suffer. Students no longer need to be taught how to search. They come to law school with that ability. Instead of focusing on individual print and electronic research tools, we need to focus on helping students understand what they are looking for, through concepts such as hierarchy of authority, and how to recognize it when they find it. This is the goal of legal information literacy.

At Temple, the first research project has, for the most part, been a highly structured, multistep research report that sent students through the library before asking them to pursue a similar research path online. Using information literacy as our guide, this year we focused more on what to look for-cases, statutes, and other authoritiesand asked much more open-ended questions 
about what they found. ${ }^{16}$ We introduced the major legal research search engines, but did not direct the students to start in any particular place. We followed this up with a discussion of their results.

This was the first step in adopting an information literacy-based legal research framework, and it was successful, largely because students were familiar with Google and the types of results it might produce. The students all achieved the goal of identifying relevant authority for this first assignment. While it was nerve-wracking to give the students such free reign, the positive results showed that the information literacy model could work.

\section{Principle No. 2: Focus on evaluating, not} finding.

Whereas a bibliographic research process requires familiarity with "finding tools" such as digests and indexes, online research, for the most part, does not. It is now nearly impossible to complete a search box search that gets you zero results; even a poorly constructed search will yield something. Instead, new legal researchers must be taught to ask the right questions when evaluating their search results. For example, we presented our students with this list of questions one can ask when evaluating a source:

- Is it law?

- If it's law, is it my law?

- If it's my law, is it useful law?

- If it's not law, or not my law, is it useful in some other way?

- Is it credible?

n- Is it permanent?

Through this list of questions, we can cover some of the basic concepts in legal research under both a bibliographic or information literacy paradigm - primary and secondary authority, mandatory and persuasive authority, and evaluating and updating source material.

${ }^{16}$ For example, one of the first questions in the research assignment was "Try a search on Google. What did you find?"
Part of this instruction also involves teaching students to take ownership of the search. In an online environment, there are many tools presented under the guise of "helping" that may pull the researcher away from the intended research path (and in so doing, cost a lot more money). Being mindful of the purpose of one's search, and knowing that there are tools such as autofilled search boxes and crowdsourced algorithms, allows students to exercise self-control and selfawareness to stay on their intended research path.

Principle No. 3: Move away from linear research plans.

For a long time, legal research has been presented as a process with a beginning and an end, with some recursive steps taken in the middle of a mostly linear path. Now, by asking students to start researching at a point that feels natural to them, we have taken a step away from this start-to-end way of thinking.

The new online research tools facilitate this type of research. For example, consider the following answer to this question, offered in a students' research report:

Try at least two source-driven searches using any two of Westlaw.com, WestlawNext, Lexis. com, or Lexis Advance. Identify your search terms and describe the process and results.

Using Westlaw.com we searched the database for U.S. Supreme Court Cases decided after 1945 using Hostile Work Environment + Sexual Harassment to find relevant cases. We found it much more difficult to find relevant cases without having secondary sources to guide us and we found the process of finding relevant secondary source databases to be challenging. Content driven searches on Lexis Advanced and WestlawNext easily allowed us to move back and forth between helpful secondary sources, related cases, and federal statutes. Because we could not easily move between databases, this process was much longer and more complicated using a sourcedriven search.
${ }^{6}$ While it was

nerve-wracking to

give the students

such free reign,

the positive

results showed

the information

literacy model

could work." 
${ }^{66}$... the transition

to a paradigm

based on

information

literacy must

be marked by

an increased

focus on process

and hands-on

research."
Under a traditional legal research instruction model, we might have guided the students to a particular secondary source to start with. These students jumped right into the research, and in so doing, learned firsthand the value of using secondary sources. They also developed a preference for content-driven searches for this research question, because this type of search allowed them to move with fluidity from secondary to primary sources until they felt they had the right information. As teachers, we need to let go of the idea that there is a "right" place to start research and a "correct" subsequent research path that follows. Focusing on information literacy rather than use of particular sources allows us to get away from that linear thinking.

Principle No. 4: Reframe what it means to learn by doing.

In the classroom, the transition to a paradigm based on information literacy must be marked by an increased focus on process and hands-on research. For example, one common method of introducing students to legal sources and the legal research process involves lecture-based instruction about mandatory and persuasive authority and primary and secondary sources, followed by a structured research assignment with questions designed to expose students to the basic bibliographic sources required for the assignment. ${ }^{17}$ The information literacy paradigm might flip these steps, so that the professor first sends students to research a problem based on a brief discussion of what they need, without any direction about which resources to use or how to use them. The professor then brings the students back to class to evaluate the results. The ensuing discussion would then involve an analysis of their research results that includes categorization and evaluation of the different types of sources they found, as well as a review of their search techniques and evaluation of various resources.

17 See Ellie Margolis \& Susan L. DeJarnatt, Moving Beyond Product to Process: Building a Better LRW Program, 46 Santa Clara L. Rev. 101-103 (2005). The organization of most legal research textbooks reflects this approach. See, e.g., Sloan, supra note 7 at 74-76
Principle No. 5: Rethink certain traditional approaches to the first-year course.

Finally, successful adoption of an information literacy paradigm probably means abandonment of certain components that exist in some (if not all) first-year legal research and writing programs. These include stand-alone training in Computer-Assisted Legal Research, offering separate training on "free" legal research sources, and using closed-packet problems.

Information literacy requires that legal research instruction include all of the available online research tools, which might mean staffing legal research training differently than is currently done. At many schools, service provider representatives conduct online legal research training, either through guest lectures/class visits or separate, mandatory training sessions. Information literacy requires integrating this into the course itself.

It also means dissolving the distinction between "free" and "paid" legal services. At many schools "online legal research" training involves the paid legal services, and "free" or "cost-effective" legal research training is done separately and later. Now, we must tackle all of these at once.

Finally, information literacy contemplates an integration of research and writing that is not present in closed-packet assignments. The "learning by doing" inherent in an information literacy paradigm brings understanding of sources through use of sources. According to the 2012 ALWD survey, only forty-three schools offer all open library research for writing assignments. ${ }^{18}$

In order to prepare practice-ready students, able to cope with the ever-changing research environment, we must move away from traditional methods of teaching legal research. Information literacy offers a new paradigm to teach legal research more effectively.

(C) 2014 Ellie Margolis and Kristen Murray

18 ALWD 2012 survey results question 19c. Twenty-one schools use all closed-universe writing assignments in the first-year course. 